\title{
Los condicionantes operativos de los patrimonios municipales: de la patrimonialización de las donaciones municipales a los condicionantes normativos del Patrimonio Municipal del Suelo
}

\author{
Ángel Sánchez Blanco \\ Catedrático de Derecho Administrativo \\ Universidad de Málaga
}

\begin{abstract}
Sumario: I. INTRODUCCIÓN. II. EL MINISTERIO DE DEFENSA Y SU AJURÍDICA VOLUNTAD DE PATRIMONIALIZAR LAS DONACIONES RECIBIDAS DE LOS MUNICIPIOS. $1 .^{\circ} \mathrm{El}$ contundente pronunciamiento jurisprudencial propiciado por el intento de apropiación de los terrenos que ubicaron los acuartelamientos y el campo de tiro de Lugo, sin respetar el marco jurídico de la donación de terrenos para su construcción por el Ayuntamiento de Lugo. 2. ${ }^{\circ}$ El necesario retorno a la sensatez de la Ley de la Jefatura del Estado de 14 de marzo de 1942, de creación de las Juntas Centrales de Acuartelamiento y la necesidad de que la Gerencia de Infraestructura y Equipamiento para la Defensa del Ministerio de Defensa integre en su operativa jurídica la regulación civil de la donación. III. LAS DISFUNCIONES POLÍTICAS Y ECONÓMICAS QUE CONCURREN EN EL PATRIMONIO MUNICIPAL DEL SUELO. $1 .^{\circ}$ El origen, la funcionalidad y la progresiva relativización del Patrimonio Municipal del Suelo por su inadecuación a los objetivos a atender por los Ayuntamientos en el ámbito urbanístico. 2. ${ }^{\circ}$ El sostenimiento del Patrimonio Municipal del Suelo, en su previsible desaparición, por la Ley del Suelo de 1990. 3. ${ }^{\circ}$ La disfunción del Patrimonio Municipal del Suelo en relación con los Tratados comunitarios y con la voluntad municipal expresada en Ayuntamientos que pueden ser identificados con paradigmas urbanísticos. $4 .^{\circ}$ La ratificación constitucional de la obsolescencia del Patrimonio Municipal del Suelo al identificar el Tribunal Constitucional las competencias de «ordenación urbanística» con las «políticas de ordenación de la ciudad», y la necesidad de dar efectiva aplicación los Ayuntamientos al principio constitucional de impedir la especulación.
\end{abstract}

\section{INTRODUCCIÓN}

En los rigores del Estado centralizado del siglo XX, los Ayuntamientos fueron unos activos agentes que aportaron, de modo generoso, superficies sobre las que se edificaron inmuebles, que acogieron servicios del Estado.

Escuelas de Enseñanza Primaria, Institutos de Enseñanza Media, Casas Cuarteles de la Guardia Civil, Cuarteles de la Policía Armada, Comisarías de Policía, Palacios de Justicia, Cárceles, Cuarteles y Aeródromos 
Militares, polvorines y polígonos de tiro... han tenido, en su construcción, el prerrequisito de la previa disponibilidad de terrenos municipales.

Los Ayuntamientos vieron en estas cesiones un factor de dinamización para las actividades económicas del municipio y un incremento de las posibilidades de bienestar para sus vecinos.

La forma jurídica de la donación era el instrumento habitual para la entrega de las superficies municipales requeridas por las Autoridades civiles o militares, en unos casos segregadas de bienes comunales o de propios y, en otros, objeto de previa donación o venta a precio simbólico por notables locales.

En la generalidad de los casos, la aportación de terrenos municipales a los proyectos estatales ha implicado una muestra más de la generosa contribución de los Ayuntamientos a los servicios y fines estatales sin que el Estado se fijara en la posible contribución a la mejor satisfacción de las necesidades municipales.

La aplicación de las previsiones del Código Civil en materia de donaciones ha venido resolviendo hasta tiempos recientes las situaciones en las que el abandono por el Estado de los servicios prestados en las superficies cedidas, dejaba la donación sin causa, en similitud de criterio con los particulares expropiados en sus bienes para construcciones o instalaciones de servicios que, ante el cese del uso o la prestación, provocaban la reversión del bien expropiado al inicial titular.

La coherente aplicación del Código Civil se ha visto condicionada en los últimos años por criterios adoptados en el seno de los correspondientes Departamentos ministeriales que, ignorando normas de Derecho público - Ley de Patrimonio del Estado- y normas de Derecho privado - Código Civil—, han pretendido patrimonializar bienes de obligado retorno a sus originarios propietarios.

La situación creada incurre en contradicciones institucionales, ya que, en contraste con la generosa actitud del Estado en relación con los procedimientos de transferencias a las Comunidades Autónomas, en los Ayuntamientos, se transforma en la firme voluntad de conservar, como patrimonio de cada Departamento ministerial, las superficies e inmuebles donados históricamente por los municipios, situándolos en estrategias presupuestarias y patrimoniales de cada Ministerio, en contradicción con el proceso de privatización de actividades públicas y en conflicto con el cierre del proceso de descentralización política y administrativa que tiene 
aún pendiente el referente institucional de la Administración local y de su hacienda.

La histórica y generosa contribución municipal a los servicios estatales, mediante donaciones patrimoniales, tiene el riesgo de cerrarse con la instrumentalización estatal de los municipios pretendiendo patrimonializar las donaciones municipales.

En los rigurosos esquemas del Estado autoritario configurado en la postguerra civil, proyectado en el tiempo entre los años 1940 y 1979, y marcado por la configuración del municipio por la condición de uno de los tercios que articulaba la estructura representativa del Estado orgánico, junto a los representantes del tercio familiar y del tercio que correspondía a los sindicatos verticales, se delinea una figura jurídica: el Patrimonio Municipal del Suelo, situada en el marco de la Ley del Suelo de 1956, destinado a incidir, en sus inicios, en la gestión urbanística para la preparación y enajenación de solares edificables y reserva de terrenos vinculados a la expansión de las ciudades, y en las postrimerías del régimen orgánico, enriquecido en sus referencias operativas por la incorporación del porcentaje de aprovechamiento a percibir por los Ayuntamientos, conforme a las previsiones de la reforma de la Ley del Suelo de 1975.

La pervivencia de la figura del Patrimonio Municipal del Suelo por obra de la Ley del Suelo de 1990, en un momento político y económico muy diferente, aunque alentado por un voluntarismo neocentralista y acusadamente intervencionista, obliga a integrar el dato de la rotunda desautorización de la que hace objeto el Tribunal Constitucional a la Ley de 1990, por Sentencia 61/1997, de 20 de marzo, y al no menos voluntarista Texto Refundido de 1992, recordando la obviedad de la prevalencia de unas competencias autonómicas, valoración constitucional en la que confluye el Tribunal Supremo desautorizando seis preceptos más del Texto Refundido por extralimitarse en la función técnica de refundición, en Sentencia de 25 de junio de 19971.

El contexto autoritario, centralista e intervencionista que predetermina los datos que anteceden, requiere de la contraposición con la autonomía municipal, expresión de la recuperación de la libertad ciudadana que, en simultánea recuperación de la autonomía de la voluntad en el Derecho privado por directo efecto de la materialización de los derechos y libertades fundamentales, así como de la liberalización económica y de la privatización de patrimonios públicos, requiere, en clave de Derecho público,

\footnotetext{
${ }^{1}$ Pte. Mag. Sr. Barrio Iglesias, Rep. Arzdi. 5382.
} 
recuperar el principio de intervención mínima de la Administración autonómica y de la Administración General del Estado, sobre unos municipios que, en una coherente aplicación del principio comunitario de subsidiariedad, tienen que llegar a materializar la nueva Europa de la ciudades.

\section{EL MINISTERIO DE DEFENSA Y SU AJURÍDICA VOLUNTAD DE PATRIMONIALIZAR LAS DONACIONES RECIBIDAS DE LOS MUNICIPIOS}

\section{1. $^{-} \quad$ El contundente pronunciamiento jurisprudencial propiciado por el intento de apropiación de los terrenos que ubicaron los acuartelamientos y el campo de tiro de Lugo, sin respetar el marco jurídico de la donación de terrenos para su construcción por el Ayuntamiento de Lugo}

La jurisprudencia del Tribunal Supremo ha tenido ocasión de pronunciarse, con precisión y claridad, sobre las desviaciones conceptuales en las que ha incurrido la Gerencia de Infraestructuras y Equipamiento de la Defensa en relación con el Ayuntamiento de Lugo y con las superficies de los acuartelamientos que generosamente cedió al Ejército español en los años cuarenta.

Los hechos relatados por la Sentencia del Tribunal Supremo de 28 de abril de $1993^{2}$ son ilustrativos.

El Ayuntamiento de Lugo accede a lo solicitado por la otrora Comandancia de Obras y Fortificaciones del Ejército de Galicia, y cede, por acuerdos de 23 de septiembre y 21 de diciembre de 1940, al Ramo de Guerra, los terrenos que, al efecto, había adquirido, con destino a la construcción de Cuarteles de Infantería y un Parque de Automóviles, la cesión se realiza por un plazo temporal de cinco años, posteriormente prorrogado a diez.

En 1954 la Autoridad Militar cambia el uso militar de Acuartelamiento de Infantería y Parque de Automóviles para dedicarlo a Regimiento de Zapadores y solicita del Ayuntamiento de Lugo que la cesión se haga permanente, con la finalidad de inscribir los terrenos y edificios entre las propiedades y edificaciones del Ramo de Guerra. El Ayuntamiento de Lugo acuerda ratificar la cesión de los terrenos, sin limitación de plazo y con la condición de dedicarlos a los servicios del Ejército que la superioridad determine.

\footnotetext{
${ }^{2}$ Pte. Mag. Sr. Sánchez-Andrade y Sal, Rep. Arzdi. 2777.
} 
La Sentencia en su Fundamento Jurídico segundo sintetiza la problemática jurídica de los hechos relatados en los siguientes términos:

«El Ayuntamiento de Lugo dispuso gratuitamente de unos bienes a favor del Ramo de Guerra con el gravamen de dedicarlos a los servicios del Ejército, gravamen con el que fueron inscritos en el Registro de la Propiedad de Burgos, ya que en él consta la inscripción a favor del Estado, Ramo de Guerra, con destino a Cuartel de las Fuerzas del Ejército; conteniendo por tanto los acuerdos del Ayuntamiento de Lugo, antes citados, una donación modal que tiene su cabida y regulación en lo establecido en el artículo 647 del Código Civil, normativa aplicable en defecto de una normativa administrativa especial a la cesión de referencia, artículo 647, el mencionado, que autoriza la revocación a instancia del donante, del acto de liberalidad, cuando el donatario haya dejado de cumplir alguna de las condiciones que le impuso el donante; incumplimiento que paladinamente admite la resolución combatida en instancia que se produjo en relación con los bienes cedidos al Ramo de Guerra por el Ayuntamiento de Lugo, al decir que tales terrenos fueron puestos a disposición de la Gerencia de Infraestructuras de la Defensa «a la que corresponde enajenar los bienes de dominio público estatal que dejen de ser necesarios para la defensa, tras su previa y expresa desafectación y declaración de alienabilidad.»

En el mismo Fundamento Jurídico segundo, la Sala de lo Contencioso Administrativo del Tribunal Supremo corrige la argumentación del Abogado del Estado, al alegar que la condición se cumplió en la medida en que «las instalaciones se construyeron y durante muchos años se utilizan para acuartelamiento y otros servicios militares, entonces el modo se cumplió», apreciación que conduce al Tribunal a estimar que, la conclusión del Abogado del Estado,

«olvida que la carga o gravamen causa que presidió el otorgamiento de la cesión de los terrenos cedidos por el Ayuntamiento de Lugo al Ramo de Guerra, dedicar los terrenos cedidos a servicios del Ejército, dejó de cumplirse, al desafectar tales terrenos y declararlos alienables, por no ser necesarios al Ministerio de Defensa».

\section{En el Fundamento Jurídico tercero, la Sala de lo Contencioso Admi- nistrativo del Tribunal Supremo concluye:}

«Lo antes relatado evidencia que la cesión de unos terrenos hecha por el Ayuntamiento de Lugo al Ramo de Guerra en el año 1940, cesión ratificada en el año 1954, no fue una donación pura y simple, sino una donación sometida a la exigencia de ser destinados los terrenos que constituían su objeto a los servicios del Ejército, con ello, al mismo tiempo que se contribuía a un fin de interés general, la Comunidad Municipal, indirectamente se beneficiaba con la instalación de tales servicios, desaparecida la base, causa de la cesión y a cuya vigencia se subordina ésta, no sólo sería injusto, por contradecir el ordenamiento jurídico, sino incorrecto, implicando un enriquecimiento indebido, que la Administración militar siga detentando unos bienes, pretendiendo en su provecho enajenarlos, cuando estos fueron adquiridos por el Ayuntamiento de Lugo a costa de grandes sacri- 
ficios para destinarlos a un servicio del Ejército español aprovechándose de los beneficios que éste produciría a la comunidad lucense.»

El Fundamento jurídico transcrito aprecia, con meridiana claridad, la problemática de fondo subyacente en la cesión de superficies para el servicio de instalaciones militares y la confluencia de intereses entre el Ayuntamiento donante, beneficiado por la instalación, y que asume el coste de la adquisición de la superficie donada, por los beneficios que reporta a la propia Comunidad municipal. Beneficio municipal que es paralelo al beneficio que la Administración militar recibe, al verse libre del gasto presupuestario que de otro modo tendría que prever si no concurriera la donación municipal.

Es el mutuo beneficio para el Ayuntamiento y el Ejército lo que subyace a la equilibrada fórmula jurídica de la donación, que quiebra, si el Ministerio de Defensa retira las instalaciones y usos militares de la superficie donada, y que conducen a la Sala, en el Fundamento Jurídico transcrito, a utilizar el ajustado concepto de «enriquecimiento injusto», cuando el Ministerio de Defensa pretendió quedarse con la propiedad de la superficie donada condicionalmente para la radicación de instalaciones militares.

La Sentencia de la Sala de lo Contencioso Administrativo del Tribunal Supremo, con ejemplar voluntad de exhaustividad y estando en litigio la presunta titularidad de bienes fundiarios y la posibilidad de usucapión, aporta doctrina jurisprudencial de la Sala de lo Civil, y analiza las implicaciones de posibles prescripciones adquisitivas, ratificando, con la normativa y jurisprudencia civil, su construcción argumental, en una ejemplar integración ordinamental de las regulaciones legales sectoriales.

En el Fundamento Jurídico cuarto, la Sentencia aprecia:

«Esta Sala, en Sentencia de 31 de octubre de $1988^{3}$, ha declarado, que la reversión de un solar y de lo en él edificado, a un Ayuntamiento, está prevista para el supuesto de incumplirse las condiciones pactadas, entre ellas, dedicarlo a finalidad distinta de la contemplada y en cuya atención se efectuó la donación, recordando la Sentencia de la Sala Primera de este Alto Tribunal de 11 de marzo de $1988^{4}$, que la donación con carga modal del artículo 647 del Código Civil supone una institución en la que el donante ha exigido del donatario la concurrencia de un modo, finalidad, carga, motivo o recomendación cuyo incumplimiento puede dar lugar a la revocación o resolución de un contrato que en principio nació irrevocable por la sola voluntad del donante, pudiendo quedar sin efecto después por la existencia de tales incumplimientos.»

\footnotetext{
3 Rep. Arzdi. 8338.

4 Rep. Arzdi. 1960.
} 
La posible implicación de la figura de la usucapión, en función del cómputo del tiempo transcurrido ocupando los terrenos donados con las instalaciones militares en ellos radicados, es contundentemente desactivada por el Fundamento Jurídico quinto de la Sentencia:

«... no se trata de un problema de adquisición de la propiedad de tales terrenos por la Administración Militar... sino que tal adquisición que se produjo con una carga modal quedo sin efecto por el incumplimiento de ésta».

No hay, en consecuencia, titularidad del Ministerio de Defensa sobre los terrenos municipales donados por el Ayuntamiento de Lugo y con ello se recupera el funcional concepto de «usufructuario» que, con rigor conceptual, utilizó la preconsiderada Ley de 1942, reguladora de las Juntas Centrales de Acuartelamiento para el conjunto de los bienes afectos a los usos y servicios del Ejército español, y no cabe más que el retorno al Ayuntamiento donante de las propiedades donadas y desafectadas del uso militar a la que el Ayuntamiento quiso destinarlas, viendo frustrada el fin de su donación por acción unilateral del Ministerio de Defensa.

La regulación de la donación, en el Código Civil objeto de afortunado recuerdo por el Tribunal Supremo, obliga a considerar que está fuera del ordenamiento jurídico la pretensión del Ministerio de Defensa, según la cual, la donación de una superficie previamente adquirida por el municipio para un uso militar, se conserve en el patrimonio del Ejército, aun cuando deje de tener el uso militar que motivó la donación.

El Código Civil, con su autoridad de ordenamiento común, al cual afortunadamente retorna el sistema jurídico, después de los excesos intervencionistas que han caracterizado al Derecho administrativo durante los últimos decenios, es claro y preciso.

Las donaciones, como con sabia justeza ha apreciado la doctrina civilista: Albadalejo, Díaz Alabart, VALlet... ${ }^{5}$, implican un empobrecimiento para el donante que han provocado lo que ha sido calificado, en el mismo ámbito de la doctrina civilista, el «disfavor legislativo», importante precisión que si es apreciable en el ámbito privado, predeterminado por la primacía de la autonomía de la voluntad de las personas físicas o jurídicas privadas, permite comprender el «disfavor legislativo» patente en el Reglamento Municipal de 8 de marzo de 1924, al distanciarse ostentosamente de la donación como figura a utilizar por las personas jurídico públicas que, para poder llegar a satisfacer los intereses colectivos, tienen

5 Vid. la síntesis de Capilla Roncero, en Voz «Donación», Enciclopedia Jurídica Básica, vol. II, Edit. Civitas, Madrid, 1994, pp. 2614-2615. 
que operar con un especial rigor en la gestión de sus patrimonios, con la finalidad de no proyectar en el ámbito impositivo lo que puede ser satisfecho con los propios recursos patrimoniales y las rentas y beneficios que puedan generar.

El «disfavor legislativo» a las donaciones en los preceptos del Código Civil está expresado en la secuencia de preceptos del Libro III (De los diferentes modos de adquirir la propiedad), Título II (De la Donación).

La donación, como acto de liberalidad por el cual una persona dispone gratuitamente de una cosa a favor de otra que lo acepta (artículo 618 del Código Civil), requiere reparar en la categoría específica de «donación onerosa», que impone al donatario una carga que absorbe parcialmente el valor de la donación y que, conforme a la previsión del artículo 647 del Código Civil:

«La donación onerosa será revocada, cuando el donatario haya dejado de cumplir alguna de las condiciones que aquél impuso.

En este caso, los bienes donados volverán al donante, quedando nulas las enajenaciones que el donante hubiese hecho y las hipotecas que sobre ellos hubiese impuesto, con la limitación establecida en cuanto a terceros por la Ley Hipotecaria.»

La regulación que el Código Civil realiza de la donación obliga a incorporar otra precisión en relación con los efectos jurídicos que sobre el Ministerio de Defensa tiene el retorno a los Ayuntamientos que donaron superficies para instalaciones militares al ser abandonadas las instalaciones: el retorno de los frutos que haya podido percibir el Ministerio de Defensa.

Una muestra de percepción de frutos puede materializarse en la percepción por el Ministerio de Defensa de importes económicos de expropiaciones, cuya compensación económica percibida por el Ministerio debe retornar al Ayuntamiento correspondiente.

El artículo 651 del mismo Código Civil, en su párrafo segundo, dispone:

«Si la revocación se fundare en haber dejado de cumplirse alguna de las condiciones impuestas en la donación, el donatario devolverá, además de los bienes los frutos que hubiese percibido después de dejar de cumplir la condición.»

El preciso mandato del Código Civil es muy explícito y muy coherente con la liberalidad que está en la esencia de la naturaleza jurídica de 
la donación, liberalidad que está asentada en la libre asunción de una pérdida patrimonial por el donante, que asume en ejercicio de su autonomía de la voluntad y, por ello, sin condicionamientos modales externos del donatario.

Conforme a lo previsto en el Código Civil, en la medida en que se incumplan los requisitos que el donante impone a la donación, se requiere restituir el generoso dispendio que materializa la donación, mediante la transferencia al donante de lo donado y de los frutos generados.

Los hechos relatados en la Sentencia de 12 de junio de $2001{ }^{6}$ obligan a ratificar los argumentos que anteceden, en la misma ciudad de Lugo, y con ocasión de la improcedente negativa del Ministerio de Defensa a devolver al Ayuntamiento de Lugo los terrenos, donados en 1989, con destino a Campo de Tiro y radicados en el sitio de las Peñas de San Cibrao, instalaciones militares que son abandonadas por el Ministerio de Defensa en 1992.

El Tribunal Supremo casa la Sentencia del Tribunal Superior de Justicia de Galicia, que estimó el argumento del Ministerio de Defensa de considerar aplicable la figura de la prescripción inmemorial del artículo 1.959 del Código Civil y, con base en la certificación del acuerdo municipal de donación, califica la situación creada, en el Fundamento Jurídico 3. ${ }^{\circ}$ de la Sentencia:

«nos encontramos ante un negocio jurídico de carácter administrativo e innominado, celebrado entre dos administraciones públicas, por el que se ceden unos terrenos patrimoniales para una finalidad determinada, y por tanto, a falta de una normativa específica del Derecho administrativo aplicable, deberíamos aplicar, en cuanto a sus efectos y extinción las reglas de Derecho privado»,

y al considerar la causa del negocio, estima:

«La causa del referido negocio, es decir, la razón justificativa de su eficacia jurídica fue la cesión gratuita de unos terrenos municipales para que el Ejército los destinara a campo de tiro a partir del diecinueve de enero de mil ochocientos ochenta y nueve, por lo que al declarar el Ministerio de Defensa, en resolución de veintinueve de enero de mil novecientos noventa y dos, su desafectación de acuerdo con la política del gobierno, desapareció la causa que justificó la ratio essendi de aquel negocio jurídico y, por ende, su eficacia jurídica, que no pudo quedar desnaturalizada por el instituto de la prescripción por poseer el Ministerio los citados terrenos patrimoniales en virtud de una expresa autorización verbal de la Corporación municipal, plasmada documentalmente en sesión de diecinueve de enero de mil ochocientos ochenta y nueve.»

\footnotetext{
${ }^{6}$ Pte. Mag. Sr. Lecumberri Martín, Rep. Arzdi. 7760.
} 
2. El necesario retorno a la sensatez de la Ley de la Jefatura del Estado de 14 de marzo de 1942, de creación de las Juntas Centrales de Acuartelamiento y la necesidad de que la Gerencia de Infraestructura y Equipamiento para la Defensa del Ministerio de Defensa integre en su operativa jurídica la regulación civil de la donación

Los argumentos jurídicos que anteceden y la coincidencia temporal de la donación del Ayuntamiento de Lugo, en 1940, con la creación de las Juntas Centrales de Acuartelamiento, permiten apreciar la necesidad de retornar a los contenidos normativos de la coherente Ley de 1942, creadora de las Juntas Centrales de Acuartelamiento.

El artículo $1 .^{\circ}$ de la Ley de la Jefatura del Estado de 14 de marzo de 1942, al crear las Juntas Regionales de Acuartelamiento, dispuso:

«En cada Región Militar, Baleares, Canarias y Marruecos, se constituirá una "Junta Regional de Acuartelamiento", y que tendrá por misión la realización de las obras necesarias para alojamiento de las tropas y servicios, las de urbanización relacionadas con ellas íntimamente y la liquidación de los edificios, solares y terrenos usufructuados por el Ramo del Ejército, que no sean de utilidad para el mismo, todo ello de acuerdo con los planes de acuartelamiento y proyectos de Urbanización que tengan concebidos o conciban los distintos Ayuntamientos.»

El precepto transcrito ofrece el ejemplo de una respetuosa actitud por parte de los entonces Ministerios militares a lo que hoy puede conceptuarse como la autonomía local, ciertamente que no lo hace desde el actual imperativo constitucional del artículo 137 del texto constitucional de 1978, sino desde la lógica intrínseca marcada, por el común de los sentidos, de que los edificios, solares y terrenos que no sean de utilidad para el Ramo del Ejército se implementan en los proyectos de urbanización que tengan concebidos o conciban los distintos Ayuntamientos.

El tenor literal del precepto no considera la forma jurídica que haya estado en el origen de la incorporación de los bienes que han estado afectos al alojamiento de la tropa y de los servicios, por la sencilla razón de que opera con el equilibrado concepto jurídico de «edificios, solares y terrenos usufructuados por el Ramo del Ejército», preciso término jurídico que muestra la implícita identificación del precepto con la más progresiva concepción del dominio público, identificada por la maestra síntesis del profesor BALLBÉ PRUNES, en la afección al preciso cumplimiento de una función pública ${ }^{7}$, que, al dejarse de desarrollar, mediante el cese de

\footnotetext{
${ }^{7}$ Manuel Ballbé Prunes: Voz «Dominio Público», Enciclopedia Jurídica Seix, Barcelona, 1952, p. 781 .
} 
la utilización de los bienes afectos, supone la desafectación de esos bienes, sin plantearse la «dramática» alternativa de su «titularidad», por ser la persona jurídico pública simple y temporal usufructuaria del bien afecto a un uso público, a un servicio público o a la defensa nacional, en adecuación a la ejemplar sistemática del Código Civil.

Es obvio que no se puede apreciar la sensibilidad jurídica que posee el texto transcrito de la Ley de 1942 en el conjunto normativo que ha contribuido a conformar la hoy denominada Gerencia de Infraestructura y Equipamiento de la Defensa.

La inicial Ley 28/1984, que crea la Gerencia de Infraestructura de la Defensa y el Real Decreto 2698/1985, de 27 de diciembre, son producto de un momento legislativo marcado por la monetarización del dominio público con proyección sobre todos los patrimonios públicos, fueren de defensa, del sistema de transportes, o del sistema penitenciario, que ha mostrado la más lamentable imagen de la Administración General del Estado, aferrada a las desinteresadas aportaciones que, en cuarteles y cárceles, le hicieron los históricamente modestos Ayuntamientos, a los que la Administración General del Estado, a través de sus distintos morfismos organizativos, parece seguir instrumentalizando, mediante la relativización de la siempre menoscabada autonomía local, con el resultado de retorno, a la noche de los tiempos, al pretender transformar la racionalidad funcional del usufructuario en un abusivo título de propiedad.

La racionalidad jurídica requiere recuperar el sentido funcional de los bienes de dominio público expresado en la Ley de 1942, y considerar los excesos de las Gerencias de Infraestructuras como un triste episodio histórico producto de la inmadurez política y jurídica de quienes prematuramente ocuparon responsabilidades de Estado en la aún inconclusa transición política española.

Los abusos del título de propiedad que marca las actuaciones de la Gerencia de Infraestructura y Equipamiento de la Defensa no requieren especiales glosas, ni de la referida Ley de 1984, ni de su Reglamento de 1985, ni de las apostillas legislativas que materializan las Leyes de medidas fiscales, administrativas y de orden fiscal 50/1998, de 30 de diciembre, y 14/2000, de 30 de diciembre, que obligan a recordar al Ministerio de Defensa la necesidad de pensar en la Ingeniería y en la Arquitectura del Estado y dejar de utilizar los 30 de diciembre, de casi todos los años, para seguir desdibujando la estructura del Estado y las categorías jurídicas que lo tienen que articular. 
Los argumentos jurídicos hasta ahora expuestos requieren recordar, como referente último, la inexcusable premisa constitucional, expresada por el artículo 47 de la Constitución, que requiere, a efectos de que el conjunto institucional de los Poderes Públicos del Estado español cumplan el mandato constitucional de recuperar las plusvalías que la actividad urbanística genera en el sector privado, que los propios Poderes Públicos del Estado no especulen.

En contraste con la premisa constitucional de interdicción de especulación por los Poderes Públicos del Estado español, con la obvia finalidad, de poder operar con la necesaria autoridad para recuperar las plusvalías generadas en el sector privado como consecuencia de la actividad urbanística, en calidad de función pública, el Ministerio de Defensa, entre otros organismos públicos, parece propender a trasformarse en una gran dependencia de promoción inmobiliaria que, sin el menor miramiento a las necesidades de las ciudades en las que radican sus instalaciones, se ha proyectado en el ámbito de la ingeniería financiera ${ }^{8}$. Esto obliga a recordar las sensatas valoraciones que, sin acudir a otros antecedentes con actuaciones en ámbitos jurisdiccionales, a la altura del año 1992, realizó la Comisión de Investigación del Congreso de los Diputados sobre la financiación de infraestructuras ferroviarias ${ }^{9}$, remisión a las Cortes Generales y a la Empresa pública RENFE, que ilustra sobre una dinámica pública, vinculada, lamentablemente, a multiplicidad de organismos y empresas: Ministerio de Justicia, Autoridades Portuarias..., o vinculadas a empresas ya privatizadas: Telefónica, Tabacalera-Altadis, CAMPSA-Repsol... que, en una confusa práctica del necesario retorno al sector privado de áreas de actividad pública, han olvidado las coherente premisas de nuestro ordenamiento jurídico: de Derecho privado y de Derecho público, y están agraviando a las comunidades locales que generosamente realizaron aportaciones y a, los propios ciudadanos, que, en clave de Derecho público, contribuyeron a consolidarlas como consistentes patrimonios públicos, que no pueden ser objeto, ni de la incondicionada quiebra de la reglas

\footnotetext{
${ }^{8}$ El Ministerio de Defensa trabaja en estos momentos con medio millar de expedientes correspondientes a otras tantas propiedades susceptibles de ser vendidas. Hoy día, la superficie dependiente de Defensa en todo el país asciende a 1.500 millones de metros cuadrados. En el período 1996-2000, la Gerencia de Infraestructuras, encargada de tramitar los expedientes, amparó la firma de 80 convenios, la mayoría con organismos públicos autonómicos, locales o comarcales y se obtuvieron 86.393 millones complementarios al presupuesto del Ministerio en el período 1996-2000, situado en torno al billón de pesetas anuales. Vid. Alejandro Medina, Gaceta de los Negocios de 26 de junio de 2001.

${ }^{9}$ Comisión de Investigación de todos los extremos referidos a la compra de terrenos por parte de RENFE o de su filial EQUIDESA para financiar determinadas infraestructuras ferroviarias en San Sebastián de los Reyes y Alcobendas, Boletín Oficial de las Cortes Generales, Congreso de los Diputados, IV Legislatura, Serie E, n. ${ }^{\circ} 190.13$ de marzo de 1992, 97 págs.
} 
jurídicas, ni de la inasimilable sensación de la frívola apropiación de patrimonios históricos por los noveles miembros de los Consejos de Administración de empresas privatizadas.

\section{LAS DISFUNCIONES POLÍTICAS Y ECONÓMICAS QUE CONCURREN EN EL PATRIMONIO MUNICIPAL DEL SUELO}

\section{1. $^{-} \quad$ El origen, la funcionalidad y la progresiva relativización del Patrimonio Municipal del Suelo por su inadecuación a los objetivos a atender por los Ayuntamientos en el ámbito urbanístico}

El Patrimonio Municipal del Suelo es creado en el contexto autárquico y preliberalizador de la Ley del Suelo de 1956. Su finalidad fue objeto de las previsiones normativas del artículo 72 de esta histórica Ley:

«Dicho Patrimonio tendrá por finalidad prevenir, encauzar y desarrollar técnica y económicamente la expansión de las poblaciones, y se adscribirán a la gestión urbanística para la inmediata preparación y enajenación de solares edificables y reserva de terrenos de futura utilización.»

El artículo 76 de la Ley del Suelo de 1956 dispuso:

«Los ingresos obtenidos por la gestión urbanística mediante enajenación de terrenos del Patrimonio se destinarán a la conservación y ampliación del mismo»,

y su artículo 178 incorporó la siguiente redacción:

«1. A los efectos de lo previsto en el artículo 72, los Ayuntamientos a que se refiere, consignarán en su Presupuesto ordinario una cantidad equivalente al 5 por 100 de su importe durante el número de anualidades que exija el desarrollo del Plan.

2. También destinará el 5 por 100, al menos del mismo Presupuesto a la ejecución de urbanizaciones previstas en los programas de actuación.

3. Las expresadas asignaciones figurarán al mismo tiempo en el estado de ingresos de los Presupuestos especiales de urbanismo cuando existieren.»

El artículo 276.2 del Real Decreto Legislativo 1/1992, de 26 de junio, dispone:

«Los bienes del Patrimonio Municipal del Suelo constituyen un patrimonio separado de los restantes bienes municipales y los ingresos obtenidos mediante enajenación de terrenos o sustitución del aprovechamiento correspondiente a la 
Administración por su equivalente económico, se destinarán a la conservación o ampliación del mismo.»

El artículo 280 del mismo RDL 1/1992 precisa:

«Los bienes del Patrimonio Municipal del Suelo, una vez incorporados al proceso de urbanización y edificación, deberán ser destinados a la construcción de viviendas sujetas a algún régimen de protección pública o a otros usos de interés social, de acuerdo con el planeamiento urbanístico.»

Su artículo 281 reproduce los contenidos del antiguo artículo 178 de la Ley del Suelo de 1956, manteniendo, con carácter de supletorio, conforme a la Sentencia del Tribunal Constitucional 61/1997, de 20 de marzo, la previsión de un 5 por 100 del presupuesto ordinario con destino al Patrimonio Municipal del Suelo y el otro 5 por 100 precisa, enriqueciendo las iniciales referencias «a la ejecución de urbanizaciones, dotaciones públicas y operaciones de reforma interior previstas en el planeamiento urbanístico».

Los preceptos transcritos, con intencional reproducción de su secuencia histórica, obligan a realizar las siguientes precisiones.

En relación con la regulación en la Ley del Suelo de 1956, no pueden pasar desapercibidos datos como los siguientes: la postposición de la elaboración de los Planes Generales de Ordenación Urbana al momento de la constitución de los Ayuntamientos democráticos en los años ochenta, con una dinámica urbanizadora, entre los años sesenta y setenta predeterminada por Planes Parciales sin el oportuno marco del Plan General. Realidad que ha relativizado la aplicación de la legislación del suelo, por efecto de la acción combinada de renuencia social a los mandatos normativos y de la tolerancia municipal ante el incumplimiento de las previsiones normativas en detrimento de la obligación pública de cumplir y hacer cumplir la legislación urbanística. En este contexto, de hecho, y durante varios decenios, se ha relativizado también la exigencia normativa de que, para poder edificar, era necesario delimitar el solar mediante la previa o simultánea realización al hecho edificatorio de aceras, pavimentos, e iluminación. En muchos casos y con particular incidencia en las áreas urbanas periféricas de las ciudades con mayor crecimiento, ha provocado que las Corporaciones municipales tengan que subsanar estas omisiones o hacer frente al deterioro de las deficiencias de urbanización, lo que obliga a identificar la actuación municipal con la delimitación, a posteriori, de los solares que, por tolerancia municipal, no delimitaron ni los promotores ni el Ayuntamiento, en el preciso momento de la realización de las construcciones, y en vulneración de las previsiones del artículo 72 de la Ley del Suelo de 1956. 
La realización, varios decenios después, de lo que, conforme a la legislación urbanística tenía que realizarse y no se realizó, unido a lo que, por no ser realizado con la suficiente calidad, requiere, no ya la reparación sino la nueva urbanización de lo mal urbanizado, constituye parte de las exigencias a las que tiene que atender la programación urbanística de los Ayuntamientos y, en su desarrollo, realizar proyectos y ejecutar obras, que tratan de cumplir con los estándares mínimos requeridos por el viario urbano de la ciudad, ajustándose al simple concepto de «conservación» previsto por el artículo 76 de la misma Ley del Suelo de 1956 y, en un momento en que la aplicación del criterio de calidad a las dotaciones de mobiliario urbano se imponen como parámetro inexcusable en la calidad de vida de las ciudades, en unión de la falta de rentabilidad en la construcción profesional de Viviendas de Protección Oficial, se registra el hecho, frecuente en las áreas urbanas con un desarrollo urbano marcado por prácticas en la indisciplina urbanística, de tener que reconvertir las dotaciones previstas a las finalidades de construcción de vivienda hacia inversiones en infraestructuras y dotaciones urbanas, desvinculándose de las históricas previsiones normativas establecidas para el Patrimonio Municipal del Suelo y mostrando la disfuncionalidad de su conceptualización como «patrimonio separado de los restantes bienes municipales».

Las previsiones del artículo 178 de la Ley del Suelo de 1956 están complementariamente afectadas por la desaparición de la figura del Presupuesto General de Urbanismo por efecto del Real Decreto-ley 3/1981, de 16 de enero, significativo dato normativo del que hay que extraer las oportunas consecuencias relativizadoras del Patrimonio Municipal del Suelo y de la funcionalidad que tuvo en los años sesenta y setenta, con efectos positivos en la dinamización de la construcción de vivienda y como instrumento de gestión urbanística en un momento histórico en el que la conjunción de la dinámica municipal, con la del desaparecido Ministerio de la Vivienda y de la extinta Organización Sindical Española, determinaron las realizaciones urbanísticas.

El referido artículo 178, cuyo tenor es incorporado al artículo 281 del Texto Refundido de 1992, obliga a integrar los efectos de la citada Sentencia del Tribunal Supremo de 25 de junio de 1997, que acumuló a la Sentencia del Tribunal Constitucional 61/1997, de 20 de marzo, la anulación de seis preceptos más del desafortunado Texto Refundido de 1992, en este caso, al apreciar exceso en el uso de la delegación legislativa, con el efecto de relativizar el contenido y la efectiva aplicación de este precepto.

En la desaparición del Presupuesto General de Urbanismo en el año 1981 concurre el dato de la progresiva normalización de nuestras ciuda- 
des en el ámbito de la vivienda como consecuencia de la consolidación de un importante patrimonio inmobiliario, ciertamente debido a la incidencia de la iniciativa pública, y que coincide con el relevo empresarial privado y con la normalización de los parámetros presupuestarios municipales, que no pueden propender a la segregación presupuestaria de cada una de las cada vez más diversas áreas de actividad municipal y, como efecto inducido del referido Real Decreto-ley, concurre la inevitable relativización de la figura y de los contenidos del Patrimonio Municipal del Suelo.

\section{2. $^{\circ} \quad$ El sostenimiento del Patrimonio Municipal del Suelo, en su previsible desaparición, por la Ley del Suelo de 1990}

El sostenimiento del Patrimonio Municipal del Suelo, en su previsible desaparición, por la reforma de la Ley del Suelo de 1990 y por el Texto Refundido de 1992, se ha producido en conflicto con los valores de descentralización y desregulación requeridos por el nuevo marco jurídico institucional de liberalización económica y de descentralización política y administrativa, requerido por la Constitución de 1978 y la incorporación de España a la Comunidades Europeas.

La pervivencia del Patrimonio Municipal del Suelo en el Texto Refundido de 1992, con su atípica naturaleza jurídica, está también en conflicto con los objetivos de simplificación administrativa inherentes a la desregulación, y genera contradicciones que llegan al límite de provocar absurdos jurídicos en esta singular figura.

Ésta es la consecuencia que deriva de la admisión, en el artículo 276.2 del Texto Refundido de 1992, de permitir la enajenación de terrenos o sustitución del aprovechamiento por su equivalente económico y su destino a la conservación o ampliación del mismo, que permite que, en un ejercicio que ha sido calificado de autofagia, el Patrimonio Municipal del Suelo, pueda incrementarse indefinidamente, en su entidad, como consecuencia de la venta de los bienes que de él forman parte, incardinándose en una espiral de ventas al alza, distanciándose de los fines de regulación del mercado del suelo y siendo, por el contrario, un factor distorsionador más del mercado de suelo, por la posible y casi habitual contribución del Patrimonio Municipal del Suelo al incremento de los precios del suelo, efecto perverso que, por sí solo, contribuye a cuestionar la racionalidad jurídica que pueda avalar tan anacrónica como perturbadora figura.

La pervivencia del Patrimonio Municipal del Suelo como directa consecuencia de los efectos intervencionistas y neocentralistas de la reforma 
de Ley del Suelo de 1990 y de su Texto Refundido de 1992, con independencia de la problemática que en la precaria autoridad normativa de ambos textos agregó la Sentencia del Tribunal Constitucional 61/1997 y la Sentencia del Tribunal Supremo de 25 de junio de 1997, obliga a precisar los severos conflictos institucionales que plantea con los procesos de desregulación, liberalización y privatización de actividades económicas inducidos por nuestra integración en la Comunidad Europea.

\section{3. $\quad$ La disfunción del Patrimonio Municipal del Suelo en relación con los Tratados Comunitarios y con la voluntad municipal expresada en Ayuntamientos que pueden ser identificados con paradigmas urbanísticos}

El artículo 90 de los Tratados Comunitarios, actual artículo 86 del Tratado de Niza, está en directo conflicto, en su precisa regulación del principio de libre competencia, con la pervivencia de una figura, de los autárquicos años cincuenta, que pretende regular el mercado del suelo, objetivo que no pudo conseguir, ni en el probado y acreditado intento de las sucesivas Alcaldías de las ciudades de Vitoria y Burgos que, como es conocido, fueron las que, con probada voluntad, se significaron por alcanzar el más alto nivel político y administrativo por cumplir las previsiones normativas de la Ley de 1956.

El conflicto del Patrimonio Municipal del Suelo con el principio de libre competencia invita a que, del mismo modo que otros Patrimonios Públicos, desde los Patronatos de Viviendas de Funcionarios Públicos a los viejos monopolios fiscales, se integren, mediante su simple desaparición, en el proceso de reconversión institucional iniciado en 1978 con el reconocimiento de la libre iniciativa económica en el artículo 38 de la Constitución, potenciado desde 1986 con la incorporación de España a las Comunidades Europeas.

La referencia histórica al Ayuntamiento de Vitoria y a su ejemplar gestión urbanística tiene un actual y significativo dato, que nos aporta el relato de hechos de la Sentencia del Tribunal Supremo de 2 de noviembre de $1995^{10}$. El Ayuntamiento de Vitoria, por cesión de su pleno municipal, se permitió prescindir de la figura del Patrimonio Municipal del Suelo, motivando su decisión en que el Plan General de Ordenación Urbana de Vitoria operaba con el criterio de crecimiento cero para la ciudad, y acordó aplicar las partidas presupuestarias del Patrimonio Municipal del Suelo a

10 Pte. Mg. Sr. Yagüe Gil, Rep. Arzdi. 8060. 
destinos, sin duda, muy apartados de finalidades urbanísticas: atenciones informáticas, actividades en euskera, central de alarma de la policía municipal...

En opción coincidente con el Ayuntamiento de Vitoria, el Ayuntamiento de Oviedo resuelve destinar las partidas presupuestarias correspondientes al Patrimonio Municipal del Suelo a financiar 5.200 millones de deuda municipal, en calidad de concepto general sin ninguna precisión que vincule ese destino presupuestario a posibles destinos proyectados en el ámbito urbanístico, acuerdo corporativo municipal que es objeto de la Sentencia del Tribunal Supremo de 2 de noviembre de $2001{ }^{11}$.

En ambos casos, el mismo Magistrado, al enjuiciar los hechos, resuelve declarando la improcedencia de los acuerdos municipales, por la obviedad del desajuste entre las finalidades normativas previstas por la legislación para el Patrimonio Municipal del Suelo y los desviados conceptos presupuestarios a los que estas dotaciones presupuestarias fueron destinadas. En los fundamentos jurídicos de ambas Sentencias se realiza una afortunada síntesis de la normativa legal que rige el Patrimonio $\mathrm{Mu}-$ nicipal del Suelo, que considera los efectos de la jurisprudencia constitucional y ordinaria sobre el Texto Refundido de 1992 y el retorno al Texto Refundido de 1976, y de cuya síntesis de legislación considerada vigente, no es factible extraer más consecuencias, que cierta osadía de ambas Corporaciones municipales que, de modo ostentoso y sin previa motivación de los acuerdos adoptados, se apartan de los fines urbanísticos que han marcado la regulación normativa del Patrimonio Municipal del Suelo, sin que se pueda considerar convalidado por la doctrina jurisprudencial, que, en el enjuiciamiento de los hechos no se proyecta, por no haber sido suscitado por los letrados municipales, ni el ámbito de decisión autonómica municipal en la elaboración de los presupuestos, ni la posible colusión de la figura del Patrimonio Municipal del Suelo con principios constitucionales y comunitarios, concurriendo, incluso, el dato de no poder observarse en el relato de hechos, de la segunda Sentencia, el dato determinante de la extrapolación de las partidas presupuestarias del Patrimonio hacia el pago de la Deuda Pública, in genere, contraída por el Ayuntamiento de Oviedo, dato aportado por informaciones jurídicas complementarias en el contexto de la trascendencia pública que ha tenido la Sentencia ${ }^{12}$, por la voluntad de considerarla como doctrina, pero cuya ponencia ha estado in-

11 Pte. Mg. Sr. Yagüe Gil, Rep. Arzdi. 9687.

12 Datos aportados en Información Jurídica Aranzadi, página web de la editorial (www.aranzadi.es), correspondiente al día 2 de noviembre 2001. 
fluida, en identidad de ponente, por el principio de economía procesal determinado por la precedente sentencia de 1995.

\section{4. $\quad$ La ratificación constitucional de la obsolescencia del Patrimonio Municipal del Suelo al identificar el Tribunal Constitucional las competencias de «ordenación urbanística» con las «políticas de ordenación de la ciudad», y la necesidad de dar efectiva aplicación los Ayuntamientos al principio constitucional de impedir la especulación}

Nuestro texto constitucional incorpora, por sí mismo, poderosos argumentos para extinguir el Patrimonio Municipal del Suelo sin tener que acudir a los Tratados de las Comunidades Europeas.

La Sentencia del Tribunal Constitucional 61/1997, en su fundamento jurídico $6 .^{\circ}$, ya identificó la competencia de «ordenación urbanística» con las «políticas de ordenación de la ciudad, en tanto en cuanto mediante ellas se viene a determinar el cómo, cuándo y dónde deben surgir o desarrollarse los asentamientos urbanos, y a cuyo servicio se disponen las técnicas e instrumentos precisos para lograr tal objetivo».

En directa consideración de preceptos constitucionales, el artículo 47 de la Constitución vincula la actividad del conjunto institucional de Poderes Públicos, a la regulación de la utilización del suelo «de acuerdo con el interés general para impedir la especulación» $\mathrm{y}$, como la contabilidad de la generalidad de los municipios del Estado Español acredita, los Patrimonios Municipales del Suelo y, de modo específico, las enajenaciones de suelo que se realizan en subasta, son un preocupante factor en las distorsiones del precio de suelo, en menoscabo de la posición que, como Poder Público, corresponde a los Ayuntamientos, vinculados al cumplimiento de la obligación constitucional de controlar la especulación del suelo y, obligado es observar, que si se hiciera de otro modo, se aportarían manifiestos perjuicios a la coherencia del modelo urbanístico de cada una de las ciudades afectadas.

La misión de los Ayuntamientos constitucionales está marcada, conforme a la dicción del epígrafe segundo del mismo artículo 47, en recuperar las «plusvalías que genere la acción urbanística» en su término municipal, y aplicar los importes de esas plusvalías a la gestión urbanística, con el objetivo de recuperar los severos déficit urbanísticos de la ciudad, sin sentirse condicionado, ralentizado y sin dejarse obstruir, en este preciso objetivo constitucional, por argumentos vinculados a obsoletos pre- 
ceptos preconstitucionales, y extrayendo de la teoría general de la obsolescencia de las normas jurídicas todas las consecuencias que el Ordenamiento Jurídico ha extraído, con precisos mandatos de inaplicación para todos los operadores jurídicos.

En este contexto, preocupante, por las severas desviaciones que permite apreciar en el cumplimiento de los fines constitucionales, tiene que ser situada la obsoleta figura del Patrimonio Municipal del Suelo, que debe dejar de ser ya un indefinido ornitorrinco jurídico, en el que la doctrina se ha dispersado al definir su peculiar naturaleza jurídica ${ }^{13}$, y que en estos momentos ha pasado a ser un severo instrumento de perturbación para la aplicación en los municipios de una coherente política urbanística y es un factor más de la siempre preocupante ineficacia administrativa, que los Ayuntamientos de Vitoria y Oviedo han tratado de neutralizar, como «adelantados».

13 Vid. López Jurado: Los Patrimonios Municipales del Suelo. Sus caracteres y operatividad, Cemci, Granada, 1992. 